\title{
Doris Sommer en The Work of Art in the World. Civic Agency and Public Humanities
}

Doris Sommer in The Work of Art in the World.

Civic Agency and Public Humanities

Doris Sommer em The Work of Art in the World.

Civic Agency and Public Humanities

\section{Sol Serrano}

PONTIFICIA UNIVERSIDAD CATÓLICA DE CHILE, CHILE

Profesora titular del Instituto de Historia, Pontificia Universidad Católica de Chile, Chile. Master of Arts, Yale University, Estados Unidos, y Doctora en Historia, Pontificia Universidad Católica de Chile. Entre sus últimas publicaciones, se destacan: ¿Qué hacer con Dios en la República?

Política y secularización en Chile 1845-1885 (Fondo de Cultura

Económica, 2008 y 2a ed., 2009), Historia de la educación en Chile. 18102010 (Taurus, 2012 y 3a ed., 2014). Correo electrónico: sserrano@uc.cl

Nota

Documento accesible en línea desde la siguiente dirección: http://revistas.javeriana.edu.co doi:10.11144/Javeriana.cl20-40.dswa 
Doris Sommer es una mujer audaz. Ha dado demasiado testimonio de ello. Por lo mismo, es una mujer empática, cariñosa y cercana. Yo he profitado de estas grandes cualidades suyas. Y por su cariño, tomo la mala opción de que fuera una tiesa historiadora quien comentara su libro, que es puro movimiento. Lo siento por ella, lo siento por uds.; pero no lo siento por mí, pues he disfrutado intensamente su lectura, como si esta adquiriera una renovada importancia. Tomé muchísimas notas con las que creía que diría algo inspirador de tanta inspiración que me embargaba y que, por supuesto, terminaron mustias en el tarro de la basura.

Conocí a Doris Sommer personalmente - había leído su clásico Fundational Fictions - luego de una comida en que nos fuimos caminando sorteando ese frío de febrero en Cambridge, ese frío que solo los puritanos resisten y hasta escogieron. No fueron más de cuatro cuadras, pero me alcanzó a contar de Pre Text. Supongo que entendí poco, pero intuí algo. Mientras ya caminaba sola por mi calle pensé: qué maravilla es ir de vuelta. Qué cansancio tenemos los que estamos de ida y que posiblemente siempre lo estemos.

El Prólogo de la obra que hoy se presenta se titula "Welcome back!". Bienvenidos a las humanidades, nos dice, cuyo sentido primigenio fue el cultivo de la virtud cívica, fundamento de la democracia, pues es en la experiencia estética e interpretativa donde nos encontramos unos con otros desinteresadamente. La experiencia estética no es en sí ni buena ni mala, ni correcta ni incorrecta, es una experiencia creativa que nos permite convivir, podríamos decir, antes de conocernos. Desde ese juicio desinteresado nace el pensamiento crítico y finalmente el ejercicio de la libertad.

El texto transita por muchos dominios que son uno solo. Es impactante que sean tantos en solo 150 páginas. Y su estructura es consistente con su contenido, porque al final - podría decirse - es performativo, actúa su propuesta. Una propuesta que es teórica. Siguiendo a Schiller, es el arte y no las armas el que logra la libertad política. Doris traza una genealogía de aquellos pensadores y agentes cívicos que no desfallecieron ni se solazaron en el escepticismo para creer y buscar el cambio social. Le sigue Dewey, Marcuse, Freire, Gramsci, Boals, Mockus, Rancière y ahora podemos agregar... Sommer.

Por lo mismo que es heredera y renovadora de esa tradición, Doris Sommer parece ir y venir entre lo que convencionalmente llamaríamos de la teoría a la práctica, del pensamiento a la acción. Pero no es así. Por el contrario, que esa "doble atadura" es una dicotomía paralizante. Es, a mi juicio, la que tiene encerrada a las humanidades en una bodega lúgubre sin luz, alegría ni belleza. 
Por eso es que Doris no va y viene, sino que, junto con Schiller, sale de ese impasse entre razón y pasión, tiempo y eternidad, obligación y deseo en su propia narrativa. No es un recurso demagógico mío señalar que Kant, Mockus o Sarita cartonera son lo mismo y no lo son por un igualitarismo paternalista, sino porque comparten una experiencia estética donde no es el saber - iqué alivio!-, sino el gozo y la apropiación creativa la que los y nos hace iguales. Por eso el juicio estético es tan radicalmente democrático. Es cierto, podemos pasear por los jardines tomados de la mano de Schiller hasta Habermas ¡sin arrugarnos! Y así lo hizo ella.

Así, el libro trata el diseño y el relato de las muchas experiencias de intervención del arte en la vida cívica, muestra con ello la "utilidad de lo inútil".

Asistí a un taller de Doris para un grupo de profesoras primarias en Rancagua. Iba - en mi concepción tradicionalista - como observadora. Qué ilusión. En un minuto estuve recortando papeles, actuando y cantando, colgando mi papel escrito, como en todo taller Pre Text, que el libro describe en detalle. A la salida me guiñó el ojo y me dijo: "Wittgenstein". Me reí mucho, pero sobre todo sentí que el cansancio se replegaba y que había nuevos espacios. Por eso el primer capítulo se llama "Back home".

Doris Sommer nos habla de su propio proceso. En un momento podría haber optado por investigar algún tema candente de estudios culturales en América Latina. Problemas urgentes, dramáticos, importantes. Y se preguntó cuál sería su efecto académico o social. Obviamente, el objetivo era la denuncia y la protesta; pero, debido a las reflexiones en que estaba, sintió que los cursos y los libros estaban llevando a un escepticismo paralizante y no a un cambio político.

La protesta como inicio y fin de la política, nos cuenta, era en sí un síntoma de pesimismo. Sin capacidad de explorar prácticas alternativas, los intelectuales parecían encerrados, atrapados entre la rabia y la resignación. Había que buscar cambios desde el optimismo. Por ello, y para ello, hace la historia de los momentos de acercamiento y de separación del arte y de la virtud cívica. Me detengo en el más reciente, en el estructuralismo y postestructuralismo que tomaron la lingüística para argumentar que el cambio social era imposible, porque los sistemas lingüísticos se autoperpetuaban. Los estructuralistas especulativos pusieron la guinda a la torta: impulsaron una influencia antihumanista, que desestima la belleza del arte y, finalmente, toda forma de sentido.

Este libro es un puñetazo en la nariz, es un desenmascaramiento de una práctica intelectual que finalmente lleva de manera subrepticia a la violencia contra otros y contra sí mismo, porque no hay más espacio para la rabia que la rabia. 
Doris recoge el cansancio de muchos ante la hegemonía, ahora en leve retiro, de una teoría social replicada ad nauseam por la producción académica que paraliza el sentido. Esta tendencia no es inocente: es el narcisismo de un mundo que no resistió ni aceptó las derrotas de su tiempo. Es una autocomplacencia moral basada en la denuncia que en tiempos como estos resuena en muchos estudiantes, especialmente en América Latina. La proposición de Sommer, por el contrario, es una reivindicación seria y consistente de la política. Por ello, insisto, desenmascara un establishment que a mi juicio es finalmente reaccionario.

"La política, dice Doris refiriéndose a sí misma, no es una pausa en el campo de especialización propia. Para mí, los estudios literarios fueron útiles para el desarrollo cívico". No más dicotomías. Su propuesta las reúne en la vivencia, en la experiencia de construir un sentido compartido, una comunidad política.

La propuesta, sin embargo, causa escozor. Crece, pero el mundo académico lo mira raro. Cuesta creer que cuando la educación se cae a pedazos en el mundo entero precisamente en su objetivo primigenio, este debate no sea central en las humanidades La educación.... es demasiado seria para dejárselas a las escuelas de educación.

Dos preguntas me quedan: 1) ¿ipor qué no aparece el término dolor? 2) ¿Cómo se incorporan las otras humanidades a su sentido cívico y a la agencia cultural? El texto termina invitándome a que se las haga.

For English, stay tuned (para español presione un traductor).

Top down creativity, press 1

Bottom up interventions, press 2

To do something practical, press 3

Aesthetic education, press 5

To talk to the operator; press dsommer fas.harvard.edu.

Lo primero es presionar el último, para agradecer la osadía de creer en el cambio y en cada uno de nosotros. 